\title{
Losses Calculation of an Aerospace Retraction Wheel Motor with Regarding to Electromagnetic-Field Analysis Investigation
}

\author{
Pedram Asef and Ramon Bargallo Perpina \\ Department of Electrical Engineering, Polytechnic University of Catalonia-BarcelonaTech, Barcelona, CAT 08036, Spain
}

Received: December 23, 2015 / Accepted: January 06, 2016 / Published: March 31, 2016.

\begin{abstract}
A 3-D FEA (finite element analysis) transient and steady-state design proposal for high-speed with Nd-Fe-Br (reversible) magnets in aerospace application will be examined under design considerations of $n=12,000 \mathrm{rpm}$, short-duty, sinusoidal drive, low cogging, high efficiency at peak torque, and etc. for an ARWM (aerospace retraction wheel motor). In construction, the PMs (permanent magnets) fixed on the rotor core which is surface-mounted magnets retained by a carbon-fiber bandage. Redundant windings, resistant to fault propagation have accounted. Besides, an axial water-jacket housing without end-cap cooling has involved. All performed characteristic performances of the correlated ARWM will verify by comparison through 2-D and 3-D FEA results. In this paper, design process has dealing with determination of various kinds of losses such as electromagnetic and mechanical losses. In terms of both classified losses, copper, stator back iron, stator tooth, PM, rotor back iron, air-friction and sleeve losses were calculated. The 3-D end-winding effects were included in the modeled ARWM by the authors.
\end{abstract}

Key words: ARWM, high-speed PM motor, redundant winding, sleeve, end-winding, short duty, air-friction losses.

$\begin{array}{ll}\text { Nomenclature } \\ T & \text { Electrical cycle } \\ \rho & \text { Density } \\ \sigma & \text { Conductivity } \\ V_{s} & \text { Supply voltage to the controller } \\ B_{p t} & \text { Peak tooth flux-density } \\ B_{p y} & \text { Peak yoke flux-density } \\ B_{m t} & \text { Peak flux density in stator tooth on open-circuit } \\ B_{c s} & \text { Flux density in the stator core } \\ H_{c} & \text { Intrinsic coercivity } \\ D_{m a g} & \text { Density of magnet material } \\ D_{s h} & \text { Shaft diameter } \\ D_{s e} & \text { Stator outer diameter } \\ D_{r} & \text { Rotor diameter } \\ d_{c s} & \text { Stator core yoke } \\ A_{s l o t} & \text { Cross-sectional area of a stator slot } \\ S_{d} & \text { Effective slot-depth } \\ P_{a r c} & \text { PM (permanent magnet) arc }\end{array}$

Corresponding author: Pedram Asef, $\mathrm{PhD}$, research fields: electrical machinery and its drives.

$\begin{array}{ll}C P P & \text { Number of coils per pole per phase } \\ P F & \text { Power factor } \\ P_{r} & \text { Rated power } \\ n_{r} & \text { Rated speed } \\ F_{s} & \text { Fundamental frequency } \\ I_{d s c} & \text { Short-circuit current } \\ I_{r m s} & \text { Rms (root mean square) phase current } \\ J_{r m s} / p h & \text { Rms current density in phase windings } \\ \theta_{g} & \text { Angular circumferential around the air-gap } \\ B H_{m a g} & \text { Magnet energy-production } \\ k_{w} & \text { Winding factor } \\ k_{i s} & \text { Lamination space factor of the stator-core } \\ B_{g 1} & \text { Peak fundamental air-gap flux-density } \\ l_{s} & \text { Active stack stator length } \\ K_{p} & \text { Factor to include the effect of slot-leakage flux on } \\ l_{e} & \text { saturation face factor } \\ l_{i s} & \text { Stator equivalent length including effect of fringing } \\ L_{s} & \text { Length of the path of one pole-pitch as measured in } \\ m & \text { the mid-point of the stator-core } \\ N & \text { Leakage inductance/phase }\end{array}$


$p \quad$ Number of pole pairs

$Q_{S} \quad$ Total number of the stator slots

$W_{p h-s} \quad$ Width of phase separator (excluding legs)

$T_{p h} \quad$ Turns in series per phase

$\delta_{g} \quad$ Air-gap length

$\delta \quad$ Torque angle

$\kappa \quad$ Thermal conductivity

$C_{p} \quad$ Specific heat

$R_{e} \quad$ Reynolds number

$L F V \quad$ Local fluid velocity

$v_{a} \quad$ Axial velocity of the average

$\% \eta \quad$ Percentage of the efficiency

\section{Introduction}

In the application area of aerospace, highly engineered with smallest motor and sensor types are at harsh environment. High performance and precision which provided through embedded 3-D FEA (finite element analysis). Whereas the following clues have derived in the ARWMs (aerospace retraction wheel motors) design such as short-duty, low cogging, high efficiency at peak torque, banded rotor/large air-gap, redundant windings that occurs resistant to fault propagation [1], react time almost $\leq 10 \mathrm{~s}$, must withstand by two consecutive extend/retract cycles, which is flooded with the ARWM fuel, must supply $16 \mathrm{~kW}$ of mechanical output power at 12,000 rpm [2]. Through below schematic, better understanding of the application represented by Fig. 1 [3-5]. In addition, providing a mechanical gearbox to match motor speed to the required output speed operates advantageously due to very high relative torque density mechanical gearing can achieve [6]. The mechanical advantages synonymous with EMAs (electromechanical actuators) result in small, compact actuators ideal for the aerospace industry, where torque/force density, fault tolerance and reliability are of vital importance [7]. The higher torque density, the simplification and maintenance are some of their most crucial advantages leading PM (permanent magnet) machines to be noted as an attractive option [8].
In this research, baseline of the motor topography will be discussed by authors. Besides, shrinking motor dimensions until desired temperature rise has reached. In case of such a highly demanding application, HSPMSM (high-speed surface-mounted pm synchronous motor) topology proposed with proper results in terms of electromagnetic analysis and losses calculation by the authors.

For the PMs fixed on the rotor core, which is surface-mounted magnets retained by a carbon-fiber bandage because improved tensile modulus and adhesion properties over T700S type, where applications of this never twisted fiber include aircraft/airplane and high performance sporting goods, where demanding conditions require superior composite properties.

As Fig. 2 shows the construction, an axial water-jacket housing without end-cap cooling with $d_{n}$ $=34,85 \times 10^{-5} \mathrm{~m}^{3} / \mathrm{s}$ of fluid volume flow rate, $\kappa=$ $0.125 \mathrm{~W} /\left(\mathrm{m}^{\circ}{ }^{\circ} \mathrm{C}\right), \rho_{w}=1,000 \mathrm{~kg} / \mathrm{m}^{3}, C_{p}=1.88 \mathrm{~kJ} /\left(\mathrm{kg} \cdot{ }^{\circ} \mathrm{C}\right)$, $R_{e}=1.55 \mathrm{E}+04$ and $L F V=53.37 \mathrm{~m} / \mathrm{s}$ have derived in order to abound the temperature along minimizing losses.

In order to have the highest accuracy for the simulation, the maximum accessible number of elements of a competent mesh has noticed by 991,253 elements and 4,561,205 of nodes which can be seen by Fig. 3.

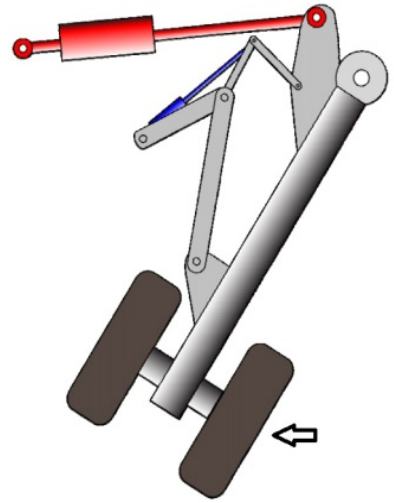

Operation time $(t>0)$

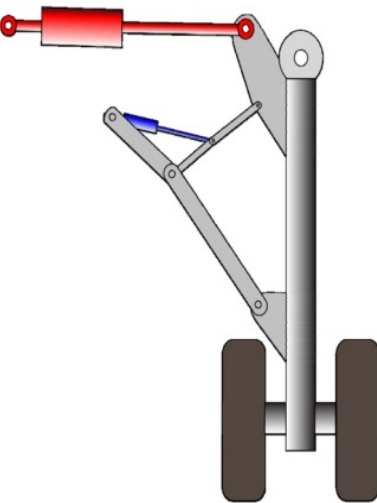

Standby time $(t=0)$
Fig. 1 Schematic of the studied ARWM for airplane application. 


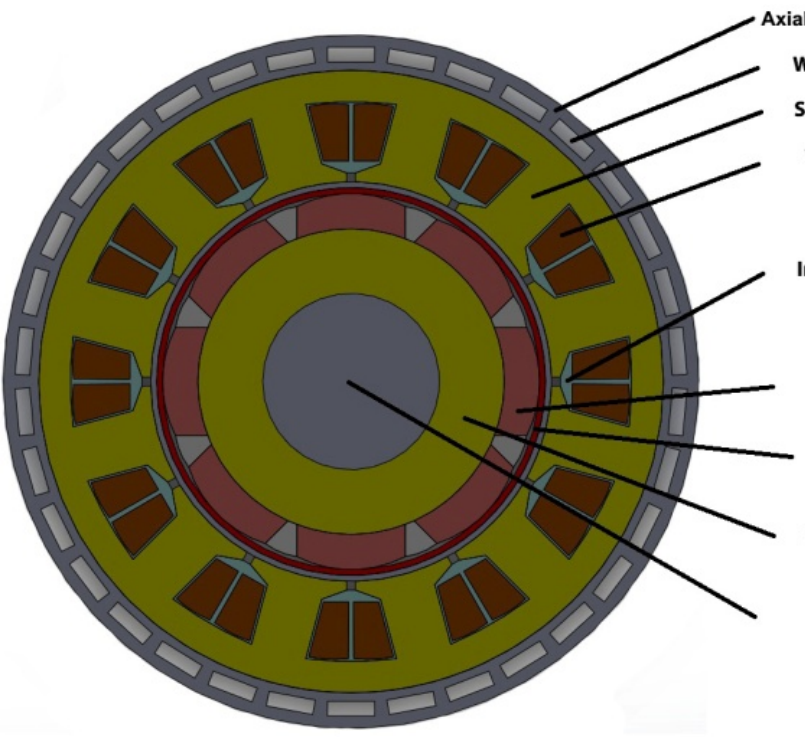

(a)

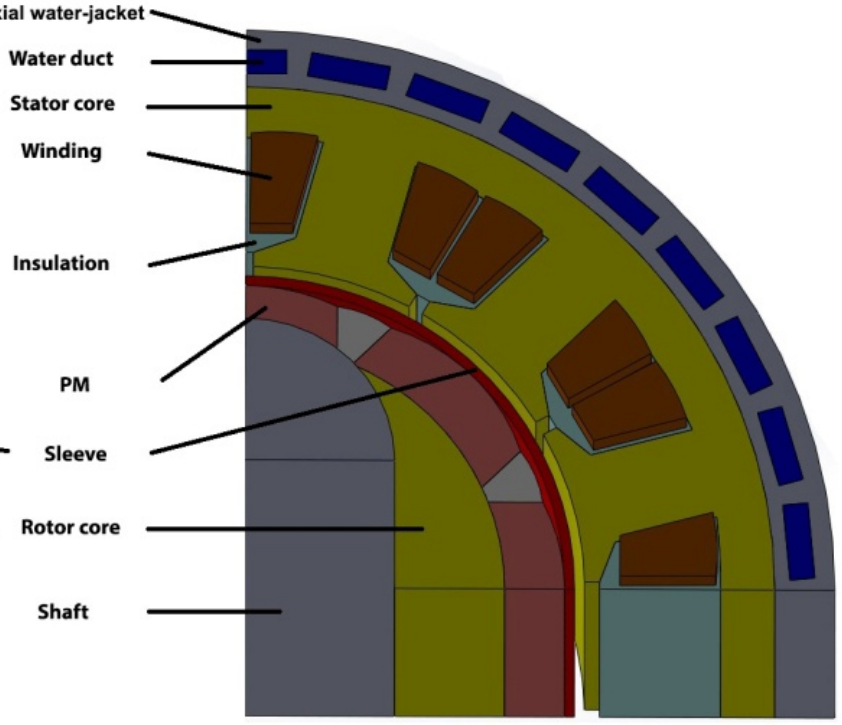

(b)

Fig. 2 Designed prototype of the ARWM in (a) 2-D model and (b) 3-D with 1/4 of whole model and 1/2 length.

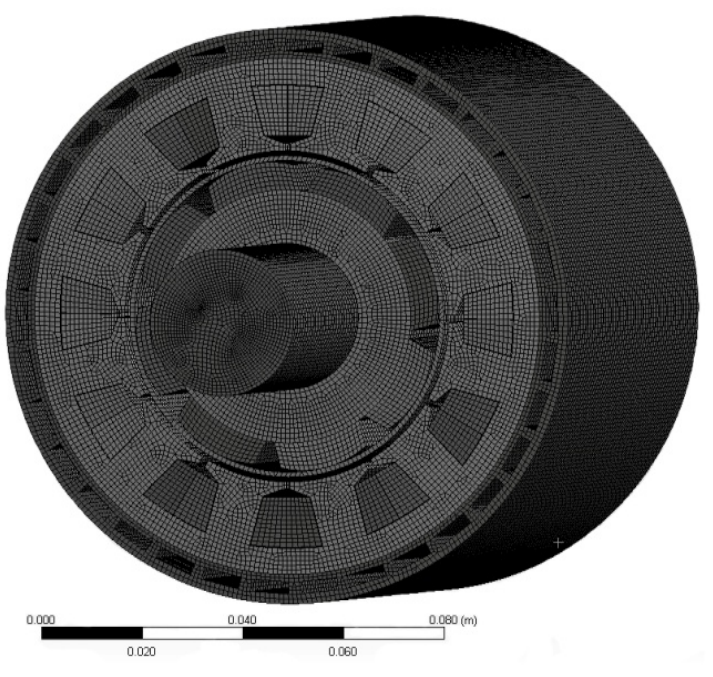

Fig. 3 Generated mesh for the whole model

\section{Electromagnetic Field Analysis through Embedded 3-D and 2-D FEA}

In terms of the chosen topology, radial-flux strategy because of the fabrication and slotted stator by standard round radial laminations, has been elected in order to maximize the electrical loading. As usually AC motors have more than 8-poles owing to be enable to have fractional-slot windings.

Here the ARWM via a 8-poles (surface-mounted PMs) in order to decrease the costs of the motor will be presented. Although, the number of poles is a function of the speed. Besides, for ignoring excessive iron losses, the flux should be confined to do not alternate in a high-frequency. Redundant windings clear-cut due to attain a sinusoidal open-circuit back-EMF (electromotive force) waveform have been accounted. According to the back-EMF and the rotor-position sensing, an AC control with sinusoidal phase current, $180^{\circ}$ conduction for each inverter leg should be used by a PWM (pulse-width-modulation) inverter with a position encoder $[4,5,9]$. In this study, design of the machine geometry data and its FEA results are held by Table 1 and Table 2, respectively.

Table 1 Design of the machine geometry.

\begin{tabular}{lll}
\hline Variable & \multicolumn{2}{l}{ Linear current density fixed } \\
\hline$l_{s}$ & 80 & $\mathrm{~mm}$ \\
$D_{\text {sh }}$ & 30 & $\mathrm{~mm}$ \\
$D_{r}$ & 64 & $\mathrm{~mm}$ \\
$D_{\text {se }}$ & 106 & $\mathrm{~mm}$ \\
$A_{\text {slot }}$ & 130 & $\mathrm{~mm}^{2}$ \\
$\delta \mathrm{g}$ & 2 & $\mathrm{~mm}$ \\
$P_{\text {arc }}$ & 130 & $\mathrm{~mm}$ \\
$S_{d}$ & 13 & $\mathrm{~mm}$ \\
$Q_{s}$ & 12 & \\
Slots/pole & 1.5 & \\
$P$ & 4 & \\
$m$ & 3 & \\
$W_{\text {ph-s }}$ & 3 & $\mathrm{~mm}$ \\
\hline
\end{tabular}


Table 2 FEA design data.

\begin{tabular}{lll}
\hline Variable & Value & Unit \\
\hline$V_{s}$ & 690 & $\mathrm{~V}$ \\
$B_{r} @ 20^{\circ}$ & 1.3 & $\mathrm{~T}$ \\
$H_{c}$ & 1,592 & $\mathrm{kA} / \mathrm{m}$ \\
$D_{m a g}$ & 7,500 & $\mathrm{~kg} / \mathrm{m}^{3}$ \\
$F_{s}$ & 800 & $\mathrm{~Hz}$ \\
$J_{r m s}$ & 15 & $\mathrm{~A} / \mathrm{mm}^{2}$ \\
$I_{r m s}$ & 34 & $\mathrm{~A}$ \\
$T_{p h}$ & 55 & \\
$I_{d s c}$ & 69 & $\mathrm{~A}$ \\
$L_{s}$ & 0.34 & $\mathrm{mH}$ \\
$k_{w}$ & 0.8 & \\
$B H_{m a g}$ & 210 & $\mathrm{~kJ} / \mathrm{m}^{3}$ \\
$B_{m t}$ & 1.6 & $\mathrm{~T}$ \\
$n_{r}$ & 12,000 & $\mathrm{rpm}$ \\
$P_{r}$ & 23 & $\mathrm{~kW}$ \\
$P F$ & 0.9 & \\
$C P P$ & 0.5 & \\
$\% \eta$ & $95.5 \%$ & \\
\hline
\end{tabular}

As in the open-circuit test, the variation of cogging torque caused by the interaction of the magnetized rotor and the slotted stator. Here the cogging torque was calculated through:

$$
T_{\operatorname{cog}}=\frac{1}{2} \cdot F_{c}\left(\frac{\mathrm{d}_{\varphi_{m}}}{\mathrm{~d} \theta}\right)
$$

The approach used in this text is somewhat the reverse of this latter method. However, two different methods have been applied in order to have extreme precision results. One is base on the local co-energy derivative which has been rated in the air-gap TVW (time-varying weight) method. Second one is the MSI (maxwell surface integral) method that is also applied in the air-gap. Both can be seen in Fig. 4.

By doing skew, here the cogging has straightforwardly been reduced as Fig. 5. Their normalized maximum harmonics have also been presented in compare with non-skewed one by Fig. 6 .

A 3-D transient magnetic flux density distribution of the ARWM under rated load condition and 2-D steady-state magnetic flux density distribution under no-load condition have been illustrated in Figs. 7 and 8. In addition, the flux paths have also been indicated in Fig. 8. By Fig. 9, a comparison between peak tooth and

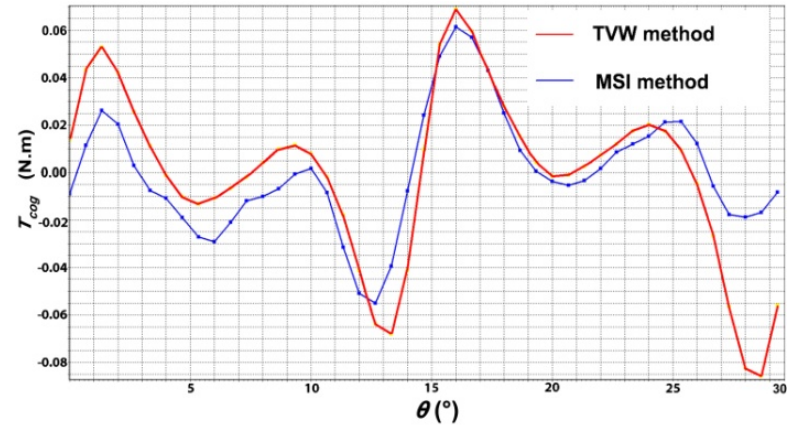

Fig. 4 Compared TVW and MSI methods to calculate cogging torque.

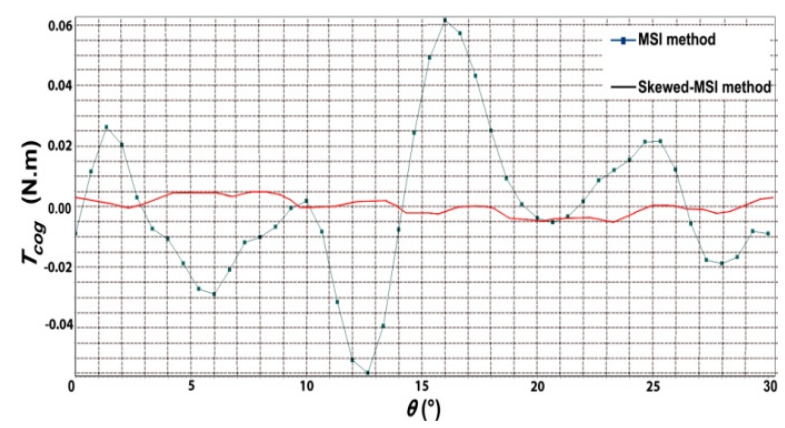

Fig. 5 Comparison between MSI and skewed-MSI results.

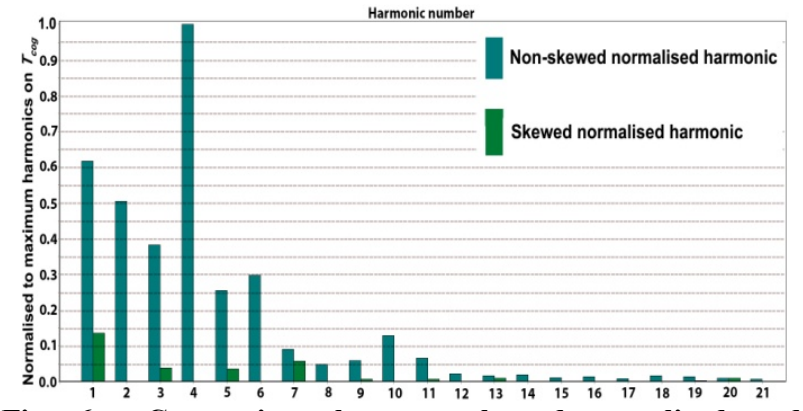

Fig. 6 Comparison between skewed-normalized and non-skewed normalized harmonics at the cogging torque.

peak yoke flux-densities under no-load condition has been showed.

In order to calculate the flux-density in the stator core (tooth and yoke), Eq. (2) can be given [10]:

$$
B_{c s}=B_{p t}+B_{p y}=\frac{\tau_{p}\left(\frac{l_{e}}{2}\right)}{d_{c s} k_{i s} l_{i s}}\left(\frac{2 B_{g 1}}{\pi}\right) \frac{1+K_{p}}{2 K_{p}}
$$

The flux-density and the EMF/turn on the tooth of the stator have been showed by comparison between 2-D and 3-D results which are soundly packed nearby themselves in below Fig. 10.

Besides, the flux-density distribution on the air-gap region via a comparison between 2-D and 3-D has been represented in the below graph Fig. 11. 


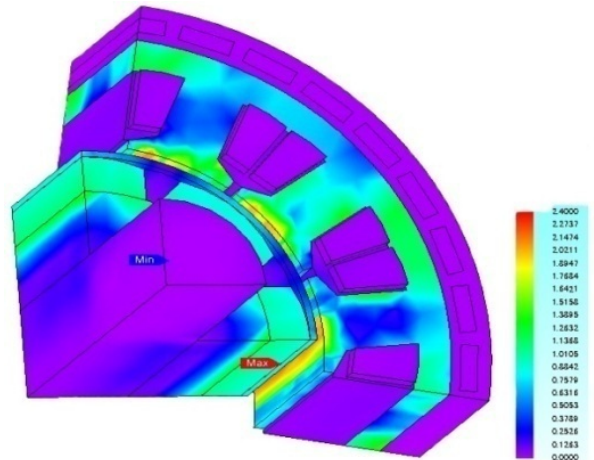

(a)

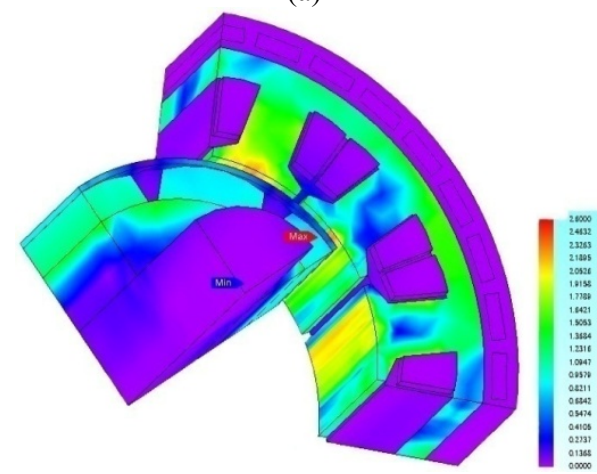

(c)

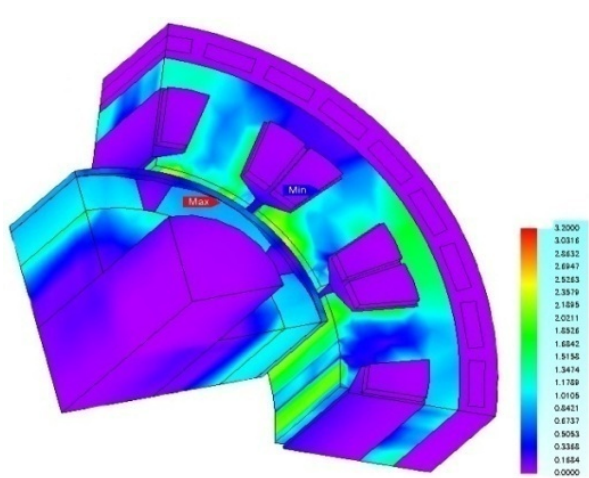

(b)

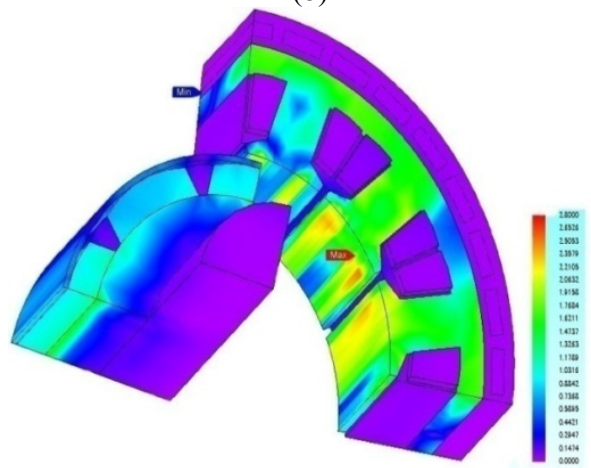

(d)

Fig. 7 A 3-D transient magnetic flux density distribution of the ARWM under rated load condition with 1/2 stack length: (a) @ $t=t=1.465 \mathrm{E}-04 \mathrm{~s}$, (b) @ $t=t=2.930 \mathrm{E}-04 \mathrm{~s}$, (c) $@ t=t=5.859 \mathrm{E}-04 \mathrm{~s}$, (d) $@ t=t=1.143 \mathrm{E}-03 \mathrm{~s}$.

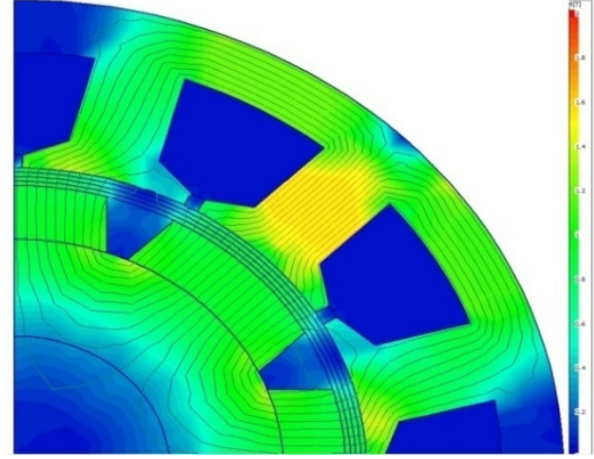

Fig. 8 2-D steady-state magnetic flux density distribution under no-load condition.

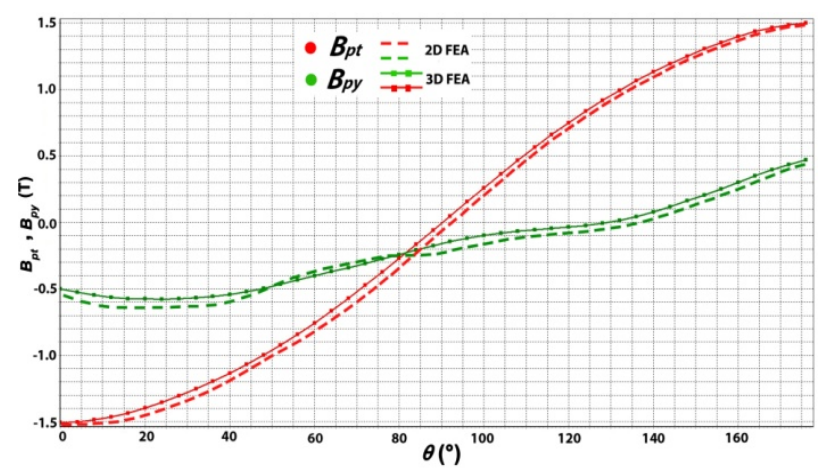

Fig. 9 Comparison between peak tooth and peak yoke flux-densities.
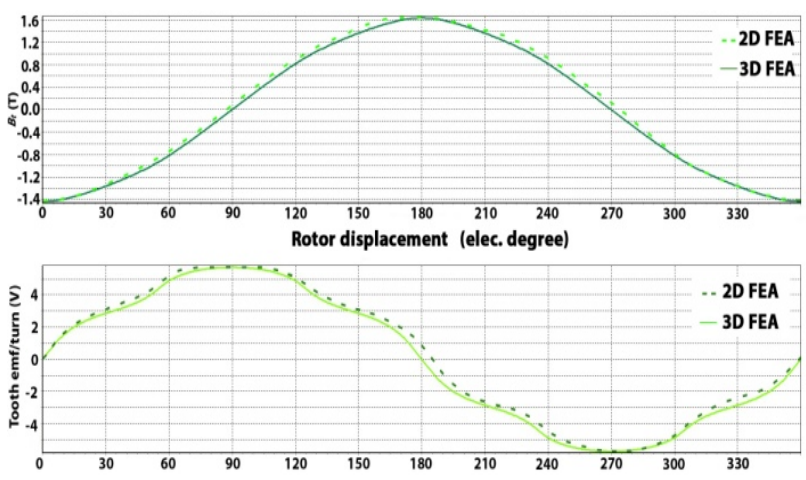

Fig. 10 Comparison between the flux-density on the stator tooth, and tooth EMF/turn in 2D and 3D.

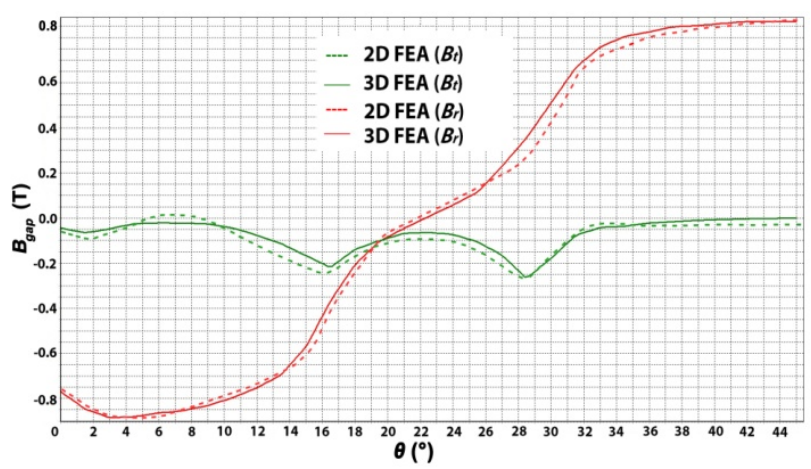

Fig. 11 2-D and 3-D results on the flux-density distribution in the air-gap region. 


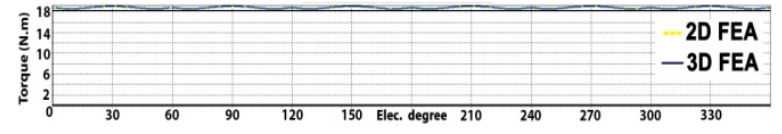

Fig. 12 The rated torque of the ARWM.

Which becomes from Eq. (3) [10]:

$$
B_{\text {gap }}\left(\theta_{g}\right)=B_{g 1} \cdot \cos \left(\frac{P \theta}{2}\right)
$$

As Fig. 12 shows that, the average torque is $18.5 \mathrm{~N} \cdot \mathrm{m}$. In this section, the paper has been evaluated the electromagnetic analysis of the studied motor through three different FEA software in order to achieve better results from simulation. As the results present, the electromagnetic manner of the ARWM was matched with what was expected in terms of characteristics.

\section{Losses Calculation of the ARWM}

In such applications with extreme synchronous speed and power density, thus, in this case, the proportion of iron loss is larger than copper loss. In this paper, iron losses included eddy-current (on the cores, PMs, and sleeve) and hysteresis losses (on the cores) what can be both calculated by below Eqs. (4) and (5) [11, 12]:

$$
\begin{gathered}
P_{h y s t}=\left.k_{h} B_{m}^{\left(a+b B_{m}\right)}\right|_{-B_{m}} ^{+B_{m}} \times\left[1+k \frac{1}{B_{m}} \sum_{i=0}^{N} \Delta B_{i}\right](4) \\
P_{\text {eddy }}=\frac{\sigma d^{2}}{12 F_{s} \cdot \rho} \cdot \frac{1}{T} \int_{0}^{T}\left(\frac{\mathrm{d} B}{\mathrm{~d} t}\right)^{2} \mathrm{~d} t
\end{gathered}
$$

where, $B_{m}, N, d, k$ and $\Delta B_{i}$ are maximum flux-density, the number of minor loops, thickness of the lamination material, a constant which will be chosen between $k=0.6-0.7$, and the flux reversal associated with a given minor loop, respectively $[13,14]$. Rotor eddy-current loss becomes the dominant loss mechanism, contributing $83 \%$ of the total loss [15].

On the other hand, Copper losses and Friction losses which both can be calculated through Eqs. (6) and (7) [6]:

$$
P_{\text {copper }}=\sigma_{c u} \cdot \sum_{n=1}^{N}\left(V_{c u}+V_{\text {end }}\right) \cdot J_{s n}^{2}
$$

where, $J_{s n}^{2}, \sigma_{c u}, V_{c u}$ and $V_{\text {end }}$ are the $n$th current density harmonic, copper conduction resistivity, copper volume along each slot, and end-winding copper volume, respectively.
In the following discussion as always, windage (air-friction) consideration must be accounted in the high-speed condition due to its higher windage loss and its effect on temperature rise of the motor. Thus, the paper argues the way that, windage losses have scrutiny been calculated in the rotor surface and the both rotor ends through results by 3-D FEA electromagnetic field analysis. In this calculation, the windage loss for overcoming drag resistance of the rotating cylinder can be calculated by Jaari's method as below [16]:

$$
P_{f}=\mathrm{k} C_{f} \cdot \pi \cdot \rho \cdot \omega^{3} \cdot r^{4} \cdot l_{s}
$$

where, $C_{f}$ is the friction coefficient that depends on the structure of the surface, $\mathrm{k}$ is a constant coefficient which was chose $1.7, \omega$ is angular velocity which is $1,130 \mathrm{rad} / \mathrm{s}$, and $r$ is the radius of the rotor $(0.032 \mathrm{~m})$. In order to calculate $C_{f}$, first through the Couette-Reynolds number $\left(R_{e_{\delta}}\right)$ for accounting the enclosure and the Axial-Reynolds number $\left(R_{e_{a}}\right)$ for accounting the axial-flow that must be calculated via below expressions [16].

$$
\begin{aligned}
& R_{e_{\delta}}=\frac{\rho \cdot \omega \cdot r \cdot \delta}{\mu} \\
& R_{e_{a}}=\frac{\rho \cdot v_{a} \cdot 2 \delta}{\mu}
\end{aligned}
$$

After that, the $C_{f}$ can be calculated by Eq. (10) as:

$$
C_{f}=\left(\frac{0.0152}{R e_{\delta}^{0.24}}\right) \cdot\left[1+\left(\frac{8}{7}\right)^{2} \cdot\left(\frac{4 R e_{a}}{R e_{\delta}}\right)^{2}\right]^{0.38}
$$

Then, by having all above parameters, the windage loss at rotor surface will be possible. However, the windage in the both rotor ends $\left(P_{f, \text { end }}\right)$ also can be important to evaluate through Eq. (11):

$$
P_{f, \text { end }}=0.5 C_{f, \text { end }} \cdot \rho \cdot \omega^{3} \cdot\left(r^{5}-r_{a}^{5}\right)
$$

where, $C_{f, \text { end }}$ for the both rotor ends has been defined as:

$$
C_{f, \text { end }}=\frac{0.146}{R e_{r}^{0.2}}
$$

The tip-Reynolds number under the condition of cylinders rotating at a free space should be given as:

$$
R e_{r}=\frac{\rho \cdot \omega \cdot r}{\mu}
$$


Table 3 Losses calculation results.

\begin{tabular}{lllll}
\hline Loss (W)/part & $\begin{array}{l}\text { Eddy-current } \\
\text { loss }\end{array}$ & $\begin{array}{l}\text { Hysteresis } \\
\text { loss }\end{array}$ & $\begin{array}{l}\text { Windage } \\
\text { loss }\end{array}$ & $\begin{array}{l}\text { Total } \\
\text { (W) }\end{array}$ \\
\hline Winding & 550 & - & - & 550 \\
Stator & 110 & 94 & - & 200 \\
back-iron & & 160 & - & 610 \\
Stator tooth & 450 & - & - & 160 \\
PMs & 160 & 6 & - & 10 \\
Shaft & 4 & - & 2 & 2 \\
Rotor-surface & - & - & 0.1 & 0.1 \\
Rotor-ends & - & - & - & 1 \\
Sleeve & 1 & 260 & 2.1 & $1,533.1$ \\
\hline Total (W) & 1,275 & & & \\
\hline & & &
\end{tabular}

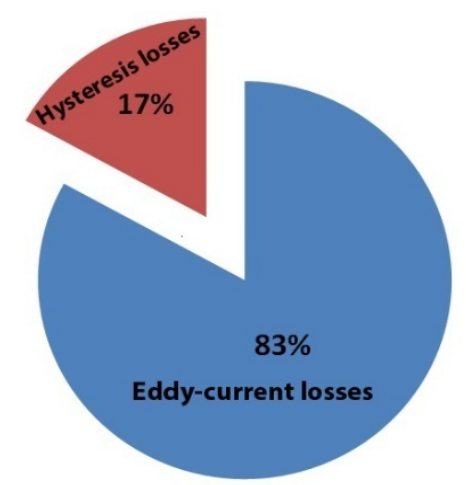

Fig. 13 The percentage of total eddy-current and hysteresis losses.

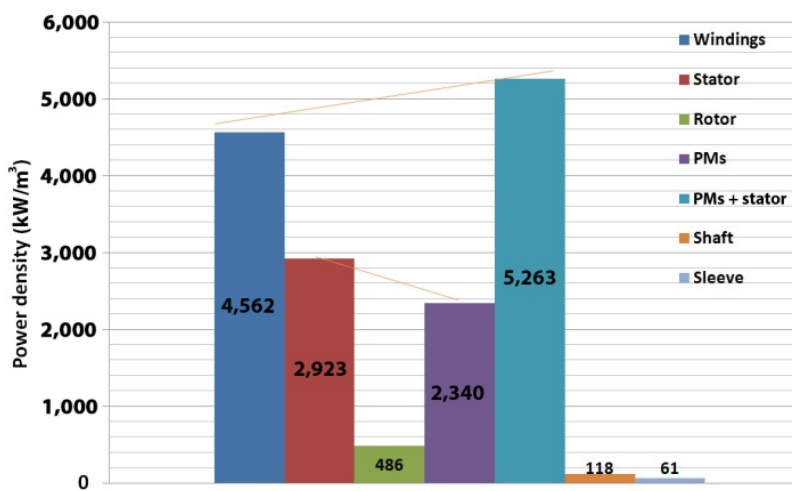

Fig. 14 Comparison of the power density by each individual part.

The following table (Table 3) summarized the calculated losses and Fig. 13 presents the percentage of total eddy-current and hysteresis losses.

Subsequent presented Fig. 14, focused on the power density value (as a compulsory value to determine the temperature distribution) in the whole motor comparability, where the power density value on the PMs and stator core aligned. Meanwhile, value of the power density on the winding has been found similarity to sum of this value on the stator core plus PMs.

\section{Conclusions}

In this paper, the various aspects of the economy problem have been considered in terms of active materials and sizing issues. The ARWM model under technical conditions for electromagnetic-field analysis has been analyzed in 3-D (transient-case) and 2-D (steady-state-case), with its notable results. Where technical conditions relied on short-duty, low cogging, high efficiency at peak torque, banded rotor/large air-gap, Redundant windings that occurs resistant to fault propagation, react time almost $\leq 10 \mathrm{~s}$, must withstand by two consecutive extend/retract cycles.

Besides, through a highly engineered design in terms of skewing, the harmonics at the cogging torque has straightforwardly been reduced in compare to the one without skewing. Thus, the cogging torque was minimized perfectly.

All the simulation results have been developed by a comparison between 3-D and 2-D results as a validation of the electromagnetic-field analysis.

With regarding to the presented electromagnetic-field analysis results, the eddy-current, hysteresis and windage losses of the model have been calculated and compared.

\section{Acknowledgment}

The authors gratefully acknowledge the contribution of Dr. D. Staton from Motor Design Ltd., UK.

\section{References}

[1] Zhao, W., Cheng, M., Hua, W., and Jia, H. 2008. "A Redundant Flux-Switching Permanent Magnet Motor Drive for Fault-Tolerant Applications." In Proceedings of the IEEE International Conference on Vehicle Power and Propulsion Conference, 1-2.

[2] Mecrow, B. C., Jack, A. G., Atkinson, D. J., Green, S. R., Atkinson, G. J., King, A., and Green, B. 2004. "Design and Testing of a Four-Phase Fault-Tolerant Permanent-Magnet Machine for an Engine Fuel Pump." IEEE Trans. on Energy Conversion 19 (4): 671-4. 
[3] Cao, W., Mecrow, B. C., Atkinson, G. J., Bennett, J. W., and Atkinson, D. J. 2012. "Overview of Electric Motor Technologies Used for More Electric Aircraft (MEA)." IEEE Trans. on Industrial Electronics 59 (9): 3226-7.

[4] Alastair, F. 2008. Practical Application of CAD in a High Power Density Motor for a Very Short Duty Aerospace Actuator. UK: Electro-Kinetic Designs Ltd.

[5] Robinson, J. I. 2007. "An Integrated Approach to Aerospace Motor Design." IEEE Trans. on Aerospace 1 (2): $847-50$

[6] Gerada, C., Bradley, K., Whitley, C., and Towers, G. 2007. "High Torque Density PM Machines for High Performance Operation." In Proceedings of the IEEE Industrial Electronics Society (IECON), 210-3.

[7] Galea, M., Gerada, C., Raminosoa, T., and Wheeler, P. W. 2011. "Considerations for the Design of a Tubular Motor for an Aerospace Application." In Proceedings of the IEEE Electrical Machines and Systems (ICEMS), 1-2.

[8] Kakosimos, P. E., Tsampouris, E. M., Kladas, A. G., and Gerada, C. 2012. "Aerospace Actuator Design: A Comparative Analysis of Permanent Magnet and Induction Motor Configurations." In Proceedings of the IEEE Electrical Machines and Systems (ICEMs), 2538-41.

[9] Dorrell, D. G., Hsieh, M., Popescu, M., Evans, L., Staton, D. A., and Grout, V. 2011. "A Review of the Design Issues and Techniques for Radial-Flux Brushless Surface and Internal Rare-Earth Permanent-Magnet Motors.” IEEE Trans. on Industrial Electronics 58 (9): 3741-6.

[10] Lipo, T. A. 2011. "Introduction to AC Machine Design." In Library of Congress Cataloging in Publication Data.
Madison, WI: University of Wisconsin-Madison, 120-7.

[11] Zhao1, N., and Liu, W. 2015. "Loss Calculation and Thermal Analysis of Surface-Mounted PM Motor and Interior PM Motor." IEEE Trans. on Magnetics 51 (11): $1-2$.

[12] Asef, P. 2014. "Design, Characteristic Analysis of PM Wind Generator Based on SMC Material for Small Direct-Drive Wind Energy Conversion System." In Proceedings of the International Conference on Renewable Energy Research and Application (ICRERA), 44-6.

[13] Gao, N., and Yu, L. 2013. "Research on Loss and Electromagnetic Heat Coupling of High Speed Permanent Magnet Synchronous Motor." In Proceedings of the IEEE International Conference on Mechatronics and Automation (ICMA), 85.

[14] Gilson, G. M., Raminosoa, T., Pickering, S. J., Gerada, C., and Hann, D. B. 2010. "A Combined Electromagnetic and Thermal Optimisation of an Aerospace Electric Motor." In Proceedings of the IEEE Electrical Machines (ICEM), 1-4.

[15] Atkinson, G. J., Mecrow, B. C., Jack, A. G., Atkinson, D. J., Sangha, P., and Benarou, M. 2006. "The Analysis of Losses in High-Power Fault-Tolerant Machines for Aerospace Applications." IEEE Trans. on Industry Applications 42 (5): 1162-8.

[16] Aglen, O. 2003. "Loss Calculation and Thermal Analysis of a High-Speed Generator." In Proceedings of the IEEE International Electric Machines and Drives Conference, 1118. 